\title{
A Corrida de Revezamento do Fogo Simbólico da Pátria em Porto Alegre (1938-1947): estudo sobre a participação dos clubes esportivos ${ }^{1}$
}

\author{
Luís Henrique Rolim* \\ Janice Zarpellon Mazo**
}

\begin{abstract}
Resumo: Este estudo tem como objetivo compreender a participação dos clubes esportivos porto-alegrenses na invenção da Corrida de Revezamento do Fogo Simbólico da Pátria (CFS) em Porto Alegre (RS - Brasil) no período de 1938 a 1947. Fontes impressas e fontes orais foram utilizadas nesse estudo. Os clubes esportivos porto-alegrenses, na figura dos seus atletas e dirigentes, ajudaram a inventar e fixar a CFS em Porto Alegre. Além disso, os clubes construíram representações da identidade nacional brasileira através da CFS.

Palavras-chave: Clubes esportivos. Corrida. História.
\end{abstract}

\section{INTRODUÇÃO}

A Corrida de Revezamento do Fogo Simbólico da Pátria (CFS) era uma prática cultural que marcava o início das comemorações da Semana da Pátria em Porto Alegre (RS) no final da década de 1930 (AMARO JÚNIOR, 1944; LIGA DE DEFESA NACIONAL, 2006). Institucionalizada pela Liga de Defesa Nacional (LDN) em 1938, era repetida anualmente com o apoio dos clubes esportivos portoalegrenses. Foram os dirigentes desses clubes que a idealizaram, após presenciarem a inédita Corrida de Revezamento da Chama Olímpica (BORGERS, 1996), na Cerimônia de Abertura dos Jogos Olímpicos de Berlim em 1936.

\footnotetext{
${ }^{1}$ Este artigo corresponde a uma parte dissertação de mestrado do primeiro autor intitulada "A Chama que arde em nossos clubes! A Corrida de Revezamento do Fogo Simbólico da Pátria em Porto Alegre (1938-1947)".

* Mestre em Ciências do Movimento Humano. Professor do Grupo de Pesquisa em Estudos Olímpicos da PUCRS. Porto Alegre, RS, Brasil. E-mail: Ihrsilva@yahoo.com.br

** Doutora em Educação Física. Professora do Programa de Pós-Graduação em Ciências do Movimento Humano. Escola de Educação Física da UFRGS, Porto Alegre, RS, Brasil. E-mail: janmazo@terra.com.br
} 


\section{Artigos Orifinais Luis Henrique Rolim e Janice Z. Mazo}

Ao retornarem para o Brasil, os dirigentes esportivos portoalegrenses decidiram pela realização de uma corrida semelhante na cidade de Porto Alegre. Na sua primeira edição em 1938, a CFS partiu de Viamão - a primeira capital do Rio Grande do Sul - e chegou a Porto Alegre. A chama foi conduzida por destacados atletas porto-alegrenses até a Pira da Pátria construída no Parque Farroupilha - conhecido como Redenção - para ser acesa à zero hora do dia $1^{\circ}$ de Setembro (CORREIO DO POVO, 1938a, p. 11).

Com o acendimento da Pira da Pátria iniciavam-se as comemorações da Semana da Pátria em Porto Alegre. Os festejos perduravam até o dia sete de setembro, data oficializada para a comemoração da Independência do Brasil e dia de extinguir o Fogo Simbólico que ardia desde o dia primeiro de setembro na Pira da Pátria da cidade de Porto Alegre.

A partir desses acontecimentos observamos que desde 1938 a CFS constituiu-se em uma das principais atividades para comemorar a Semana da Pátria em Porto Alegre, conforme sugere a reportagem: “A maior corrida do Brasil" (FONSECA, 1961, p. 66-67). Percebeu-se também que rapidamente a CFS atingiu grande destaque, não apenas local, mas também nacional. E, até o final do período do Estado Novo (1937-1945), a CFS já tinha extrapolado as fronteiras nacionais sendo considerada a "maior corrida de revezamento [em nível simbólico] do mundo" (INICIADA..., 1944, p. 10).

Embora a CFS seja realizada até os dias atuais, neste estudo nos propusemos a investigar o período de 1938 a 1947. Esse recorte temporal compreende o ano de realização da primeira corrida em 1938 até a sua décima edição em 1947, quando há indícios do enfraquecimento da cerimônia da CFS. Além disso, após o ano de 1947, evidenciou-se a construção de outras práticas culturais direcionadas à afirmação de uma identidade regional no Rio Grande do Sul (BILHAR; OLIVEN, 2006; PAIXÃO CORTES, 1994).

Tendo em vista o envolvimento dos dirigentes esportivos portoalegrenses na construção da CFS e sendo Porto Alegre sempre o ponto final da Corrida, ou seja, o local de sua culminância, o recorte espacial do estudo delimita-se a esta cidade.

Movimento, Porto Alegre, v. 15, n. 04, p. 11-33, outubro/dezembro de 2009. 
Este estudo situa-se na dimensão da História Cultural (CHARTIER, 2000; BURKE, 2005; PESAVENTO, 2004), no qual se busca dialogar com diferentes conceitos, como: Representações (CHARTIER, 2000); Tradições Inventadas (HOBSBAWM, 1988; 1984) e Identidade Nacional (SMITH, 1997). Com estas perspectivas, o estudo tem como objetivo: compreender a participação dos clubes esportivos portoalegrenses na invenção da Corrida de Revezamento do Fogo Simbólico da Pátria em Porto Alegre no período de 1938 a 1947.

\section{Percurso metodólogico}

A CFS ainda não havia sido tema de pesquisa acadêmica, sendo apenas encontradas algumas referências a sua realização em publicações que abordavam o período do Estado Novo. Nesse sentido, para atender ao objetivo desse estudo, foram garimpadas fontes impressas e também foram produzidas fontes orais através da gravação de entrevistas. As fontes históricas coletadas em diferentes locais, como acervos particulares, arquivos públicos, bibliotecas, clubes, federações desportivas, fundações, memoriais e museus foram organizadas primeiramente numa Base de Dados (ROLIM, 2008) para facilitar o entendimento das informações.

As fontes impressas primárias foram os documentos e obras da LDN; ao mesmo tempo em que trazem referências primárias, os documentos da LDN apresentam um discurso rígido e pautado, quase sempre nos mesmos autores. Dessa forma, foi comum encontrar as mesmas citações em diferentes documentos da LDN. Entretanto, utilizamos os registros da LDN como fonte primária no que tange a nomes de atletas, clubes, cidades e números das edições da CFS. Já as fontes secundárias desse estudo foram a Revista do Globo, o jornal Correio do Povo, os almanaques esportivos e obras específicas.

A Revista do Globo era uma destacada revista editada no Estado do Rio Grande do Sul pela Livraria Editora Globo no período de 1929-1967. Segundo Torres (1997) a Revista do Globo aparece para reforçar a imprensa porto-alegrense e completar uma lacuna deixada por fracassados periódicos do mesmo tipo. Foram encontrados três fascículos específicos sobre a CFS e aproximadamente 30 fascículos

Movimento, Porto Alegre, v. 15, n. 04, p. 11-33, outubro/dezembro de 2009. 


\section{Artifos Orifinais Luis Henrique Rolim e Janice Z. Mazo}

da Revista do Globo que contribuíram para o entendimento do contexto do estudo.

No jornal Correio do Povo (CP) foram pesquisadas as edições do mês de setembro entre os anos de 1938-1947, pois o critério utilizado constituía no mês de realização da CFS e nos anos das edições estudadas. Devemos lembrar que o Correio do Povo se colocava permanente como instrumento de propaganda política do regime vigente. Tanto nos seus editoriais quanto nas linhas condutoras de suas notícias era possível verificar a aproximação com a figura de Getúlio Vargas e, consequentemente, as iniciativas da LDN (TORRES, 1997).

Os almanaques consultados se constituíam como obras que compilava informações sobre esportes e variedades de anos anteriores a sua publicação. Dentre os 14 almanaques esportivos localizados para o estudo, Mazzoni (1943/1944) apresentou uma nota sobre a CFS e Amaro Jr. (1947) também se referiu diretamente a CFS. Todos os outros números desses almanaques foram utilizados para abordar o contexto do estudo.

Completam as fontes secundárias desse estudo o volume número 1 da obra "Aspectos Gerais de Porto Alegre" (PIMENTEL, 1945), e o livro "Brasileiros de cabelos loiros e olhos azuis" (DAUDT, 1952). O primeiro livro, publicado no final do regime do Estado Novo trazia oito páginas sobre o Núcleo Regional da LDN e suas principais iniciativas, entre elas a CFS. Enquanto que o segundo autor nos trouxe alguns indicativos sobre as relações entre os dirigentes esportivos que estavam presentes em Berlim (1936) e depois à frente da CFS. A obra de Daudt (1952) procura mostrar a influência dos imigrantes alemães e seus descendentes nas instituições e entidades.

Foram realizadas duas entrevistas que se constituíram nas fontes orais do estudo. A coleta dos depoimentos orais foi realizada após a aprovação do Comitê de Ética em Pesquisa da Universidade Federal do Rio Grande do Sul sob o registro do estudo número 200.7739. O critério de escolha dos participantes foi o envolvimento indireto com a CFS e, principalmente, contato direto com os idealizadores da CFS.

Os dois entrevistados serão tratados pelas iniciais MT e HL ao longo do estudo. MT é filho de Túlio De Rose e acompanhou-o ao

Movimento, Porto Alegre, v. 15, n. 04, p. 11-33, outubro/dezembro de 2009. 
longo de sua trajetória esportiva e jornalística, incluindo a CFS. HL esteve presente como audiência na primeira edição da CFS em 1938 na cidade de Porto Alegre assistindo seu pai carregar o Fogo Simbólico da Pátria. Além disso, HL é ligado ao clube esportivo porto-alegrense Grêmio Náutico União, onde teve contato com Darci Vignoli e tornouse amigo de Túlio De Rose.

As entrevistas foram gravadas para a posterior transcrição e análise junto com os outros documentos (BARDIN, 2000; MORAES, 1999; TRIVIÑOS, 1987). "Montar, combinar, compor, cruzar, revelar o detalhe, dar relevância ao secundário" (PESAVENTO, 2004, p. 65) foi o método historiográfico utilizado nesse estudo. Assim todas as fontes utilizadas podem ser pensadas como traços portadores de significados construídos para investigar o problema proposto pelo estudo. A seguir apresenta-se a análise da CFS.

\section{Os Clubes esportivos a a invenção dSA CoRrida do Fogo SimBólico}

A Corrida de Revezamento do Fogo Simbólico (CFS) enquanto tradição inventada teve como data de início o ano de 1938. Esta prática cultural surge como uma tradição enraizada no período do Estado Novo (1937-1945), mas que perdura até os dias de hoje. Neste período histórico brasileiro, onde existia uma preocupação com a construção da nação, um momento histórico fértil para a instituição de tradições no país. A CFS é uma das tantas tradições que emergiram neste momento, sendo formalmente institucionalizada e em questão de poucos anos se fixou rapidamente. Diante dessa situação e, seguindo a orientação teórica de Hobsbawm (1988), buscamos formular uma versão da CFS nas questões referentes ao seu aparecimento e fixação e não no que tange a sua sobrevivência até os dias de hoje.

O aparecimento da CFS ocorre em Porto Alegre no ano de 1938 através da sua institucionalização pelo núcleo regional da chamada Liga de Defesa Nacional (LDN). A LDN é uma entidade cívicocultural idealizada por Olavo Bilac em 07/07/1916. O Diretório Central desta entidade foi instalado na Biblioteca Nacional na cidade do Rio de Janeiro (LIGA DE DEFESA NACIONAL, 1983). O objetivo

Movimento, Porto Alegre, v. 15, n. 04, p. 11-33, outubro/dezembro de 2009. 
permanente da LDN, segundo registro na Ata de fundação lavrada de próprio cunho por seu fundador seria: estimular o patriotismo consciente e coesivo; propagar a instrução primária, profissional/ militar e cívica; e defender com a disciplina o trabalho; com a força a paz; com a consciência a liberdade; e com o culto do heroísmo a dignidade da nossa historia e a preparação do nosso porvir (BILAC, 1916 apud LIGA DE DEFESA NACIONAL, 2006).

Devido ao fomento do processo de nacionalização no país no período do Estado Novo brasileiro (1937-1945), a LDN parece ganhar força, pois estava alinhada com os ideais governamentais daquele momento. Nesse sentido podemos perceber a instalação de Diretórios Regionais e Núcleos Municipais sob a guarda do Diretório Central da LDN. Desta forma, a instituição parece ganhar membros e 'braços' para alcançar a sociedade brasileira. Um desses 'braços' e, podemos dizer, um 'braço forte', foi instalado no Rio Grande do Sul em 12/10/1937.

A escolha do Estado do Rio Grande do Sul, talvez esteja ligada ao problema da "falta de união dentro da federação" (BILAC, 1916 apud LIGA DE DEFESA NACIONAL, 2006). Visto que o Rio Grande do Sul e, mais especificamente, sua capital Porto Alegre eram conhecidos pela expressiva presença de imigrantes alemães e seus descendentes. Inclusive, Porto Alegre nos anos 1920 era identificada como a "cidade dos alemães" (PESAVENTO, 1994) devido às influências desses imigrantes tanto no campo econômico quanto sociocultural.

Com a marca cultural impressa pelos "brasileiros loiros de olhos azuis" (DAUDT, 1952), a cidade de Porto Alegre, diferenciava-se do centro do país. Embora os porto-alegrenses tivessem como referência as grandes metrópoles do Brasil - Rio de Janeiro e São Paulo - na busca de sua modernização, devido a essa identificação cultural com os alemães a cidade também estava atenta aos padrões de ser moderno e das notícias advindas de outro país: a Alemanha.

Para se ter uma ideia do 'impacto alemão', no que tange nosso objeto de estudo, ressaltamos que a Revista do Globo publicou oito fascículos ${ }^{2}$ no ano de 1936 com notícias sobre os Jogos Olímpicos

2 Os fascículos da Revista do Globo que focalizam a temática dos Jogos Olímpicos de Berlim no ano de 1936 são os de número 168, 177, 181, 186, 188, 189, 194 e 195.

Movimento, Porto Alegre, v. 15, n. 04, p. 11-33, outubro/dezembro de 2009. 
de Berlim. Além disso, cabe destacar que o estreitamento das relações com a Pátria de origem dos imigrantes alemães ocorria desde a segunda metade do século XIX, quando instrutores alemães de ginástica e de outras práticas esportivas vinham atuar nos clubes esportivos de Porto Alegre. Alguns imigrantes e descendentes de alemães, dentre eles ginastas porto-alegrenses, também viajavam para a Alemanha não apenas para visitarem parentes, mas também para conhecer os institutos de ginástica (MAZO, 2003).

Nesse sentido podemos sugerir que o deslocamento de portoalegrenses para assistir os Jogos de Berlim não foi mero acaso. Dalmáz (2002) retrata, a partir de pesquisa sobre as reportagens da Revista do Globo, as divisões de relacionamento entre Brasil e Alemanha em diferentes momentos. Segundo o autor, de 1933 a 1936 existia um período de desconfiança e entusiasmo. Nesse sentido, a ida aos Jogos de 1936 era uma oportunidade para se ver in loco a chamada concepção moderna de sociedade alemã, na qual as práticas corporais e esportivas tinham um papel de destaque.

A busca de padrões modernos na cidade de Porto Alegre não se configurava somente através do campo cultural. As iniciativas do governo estadual e municipal já haviam começado um processo de mudança no modo de vida dos porto-alegrenses. As transformações que Porto Alegre sofreu para se tornar uma cidade 'moderna' foi o suporte necessário para a realização de grandes acontecimentos públicos, como as comemorações da Semana da Pátria e a CFS (MONTEIRO, 1992).

Entretanto o fato da identidade étnico-cultural da cidade estar ligada aos imigrantes alemães merece destaque; aja visto que foi através da ida de dirigentes esportivos porto-alegrenses aos Jogos de 1936, que assistiram a chegada do inédito Revezamento da Chama Olímpica na Cerimônia de Abertura, que puderam se apropriar dessa prática e inventarem a CFS em Porto Alegre.

Mas quem eram esses porto-alegrenses que estavam presentes nos Jogos Olímpicos de Berlim em 1936? No meio dos espectadores da Cerimônia de Abertura desses Jogos, estavam entre os membros da delegação da Confederação Brasileira de Desportos (CBD), os seguintes dirigentes e associados dos clubes esportivos de Porto Alegre:

Movimento, Porto Alegre, v. 15, n. 04, p. 11-33, outubro/dezembro de 2009. 
Túlio De Rose e Ernesto Capelli, ambos ligados ao Club Italiano Canottieri Duca degli Abruzzi e a Federação Gaúcha de Remo; José Carlos Daudt, representante da Liga Atlética Rio Grandense e da Turnerbund ${ }^{4}$ e Darci Vignoli do Turnershaft $t^{5}$ e, posteriormente, membro do núcleo regional (RS) da Liga de Defesa Nacional. Naquele momento Túlio De Rose estava também como enviado da Empresa Jornalística Caldas Júnior.

O depoimento de MT informou que Túlio "estava apenas encarregado de enviar notícias sobre os Jogos de Berlim, porém ficou impressionado com a celebração e com a Corrida de Revezamento da Chama Olímpica". A intensidade emocional causada pela Corrida de Revezamento da Chama Olímpica em Túlio De Rose e na multidão reunida no estádio revela como foi potencializada uma prática cultural que mais tarde se tornaria um dos símbolos dos Jogos Olímpicos da Era Moderna (INTERNATIONAL OLYMPIC COMMITTEE, 2002). Além disso, segundo o depoimento de MT:

A delegação gaúcha se entrevistou com o Hitler [...] porque sabia que no Rio Grande do Sul havia muitos imigrantes alemães, conhecia muita coisa de Blumenau, que sabia que o Rio Grande do Sul era próximo de Blumenau e, deu de presente para o meu pai [Túlio De Rose] uma baioneta, um canivete que era uma baioneta $[\ldots]$

Todos esses estímulos parecem ter atingido Túlio De Rose a ponto de conceber "a idéia de fazer uma corrida semelhante em nossa pátria, unindo os filhos de todos os estados numa reafirmação simbólica da unidade nacional" (AMARO JR., 1944, p. 40). O hiato entre o retorno de Berlim (1936) e a realização da $1^{\text {a }}$ edição da CFS no ano de 1938 em Porto Alegre, pode ser considerado com o período em que Túlio De Rose ficou buscando formas de viabilizar o projeto da corrida da Chama Olímpica em Porto Alegre.

\footnotetext{
${ }^{3}$ Conhecido também por Clube dos Italianos. Após o processo de nacionalização passou a ser chamado de 'Clube de Regatas Duque de Caxias' (MAZO, 2003).

${ }^{4}$ Último clube esportivo alemão a se nacionalizar. A partir de 1942 passou a ser chamado de Sociedade Ginástica Porto Alegre 1867, conhecido atualmente como SOGIPA (MAZO, 2003).

${ }^{5}$ Clube de remo fundado por descendentes de imigrantes alemães em 1906. Depois do processo de nacionalização o clube passou a ser chamado de Grêmio Náutico União (MAZO, 2003).
}

Movimento, Porto Alegre, v. 15, n. 04, p. 11-33, outubro/dezembro de 2009. 
A atuação de Túlio De Rose como jornalista para o jornal Correio do Povo de Porto Alegre e sua ligação com a Federação Gaúcha de Remo e com o Clube de Remo dos Italianos facilitaram os contatos para levar adiante essa iniciativa. Porém, para realizar uma corrida de caráter simbólico, Túlio De Rose necessitaria enfrentar alguns obstáculos, como estradas esburacadas e sem asfalto, convocar atletas sem oferecer premiação e, principalmente, justificar a importância de realizar uma prática de caráter simbólico, que em um primeiro momento tinha uma relação direta com os Jogos Olímpicos.

Apesar destes aspectos pouco favoráveis à realização da CFS, Túlio De Rose conseguiu depois de dois anos efetivar seu desejo. Essa realização se deu, em grande parte, em função da relação de amizade que Túlio De Rose possuía com Darci Vignoli, que também esteve presente em Berlim e era membro do Núcleo Regional da LDN e do clube esportivo Grêmio Náutico União. A ligação entre Darci Vignoli e Túlio De Rose parece ser relevante para afirmar que foi através de Vignoli que Túlio encontrou um aliado que circulava entre os membros da LDN para a realização da CFS. Segundo o depoimento de HL:

Túlio incentivou aos dirigentes da Liga de Defesa Nacional, especialmente ao presidente e amigo Capitão Darcy Vignoli para a realização de grandes eventos esportivos, cívicos e culturais [...] Graças ao seu prestígio [de Vignoli] junto aos órgãos esportivos federais e a sólida amizade com o presidente Getúlio Dornelles Vargas, foi possível consolidar a Corrida do Fogo Simbólico no Brasil, sempre organizada e dirigida por Túlio De Rose.

Entretanto, a instituição da CFS nos registros da LDN, aparece na figura do Major Ignácio de Freitas Rolim. O Major Rolim parecia sempre estar à frente das realizações esportivas realizadas pelo governo, ${ }^{6}$ sendo assim, ressaltamos que ele estava à frente do Núcleo Regional (RS) da LDN em 1937 e 1938. Dessa forma, foi ele quem oficializou a realização da $1^{\text {a }}$ CFS em 1938, como uma cerimônia que abriria

${ }^{6}$ Para um maior entendimento ver Castro (1997).

Movimento, Porto Alegre, v. 15, n. 04, p. 11-33, outubro/dezembro de 2009. 
as comemorações da Semana da Pátria na cidade de Porto Alegre (PIMENTEL, 1945).

A justificativa para o aparecimento da CFS em 1938 estava muito atrelada à relação histórica que foi estabelecida a ela. Surge a ideia do fogo, por se tratar de um elemento natural que "vem acompanhando o homem desde os primórdios da sua evolução" e por sua presença no Movimento Olímpico na forma de Chama Olímpica que tinha como objetivo a "união das raças" (LIGA DE DEFESA NACIONAL, 2006).

Nesse sentido outras obras 'oficiais' da LDN (SAFADY, 1960; 1971) que foram consultadas sustentam essa ideia, pois ao permitirem a publicação de crônicas, poemas e escritos dos chamados nacionalistas sobre a CFS reforçam as justificativas de aparecimento da CFS. Além disso, a justificativa para a realização da CFS estava alicerçada em ligações sagradas e históricas construídas através dos meios de comunicação do período estudado.

Um exemplo disso pode ser encontrado no jornal Correio do Povo, onde se destina um destaque especial para a chegada da CFS em sua primeira edição (CORREIO DO POVO, 1938b). As publicações procuravam passar a ideia de que a CFS seria apenas uma continuação de algo já estabelecido no passado das grandes civilizações históricas e vencedoras (O FOGO, 1938a, p. 5; O FOGO, 1938b, p. 5; O FOGO, 1938c, p. 5). Assim, buscava-se justificar na cidade de Porto Alegre uma prática cultural que ajudaria a construir e tornar o Brasil um grande país.

Para atingir uma fixação, Hobsbawm (1984) define que as tradições inventadas devem ser um conjunto de práticas normalmente reguladas por regras tácitas ou abertamente aceitas, sendo essas práticas de natureza ritual ou simbólica. Nesse sentido convém pensarmos se não havia regras formais para a CFS. Não encontramos nenhum registro, dentro do período estudado, sobre regras formais e/ou instituídas para a realização da CFS. Parecia sim, haver 'regras tácitas ou abertamente aceitas' para a organização da CFS.

Podemos identificar elementos comuns e outros que foram variáveis na construção da CFS dentro dos limites do estado do RS. Esses elementos parecem depender da organização na cidade em

Movimento, Porto Alegre, v. 15, n. 04, p. 11-33, outubro/dezembro de 2009. 
que a CFS está passando. De acordo com as informações recolhidas, podemos registrar os elementos comuns da CFS: Inicia-se a CFS através de uma cerimônia de acendimento da tocha; logo após existe a passagem da tocha aos atletas; que começam o revezamento pelas cidades; até a chegada na cerimônia de acendimento da Pira em Porto Alegre.

Portanto, a fixação da CFS parece ter sido estabelecida por regras tácitas nos locais onde perpassava, ou seja, a base da CFS, que era de sair de um ponto e chegar a outro, continuava inalterada. Porém, nas localidades onde perpassava seu formato era construído pelas autoridades do local. Isso de certa forma mantinha o ineditismo da CFS e fazia com que a comunidade das localidades onde ela cruzava se identificassem com a CFS.

Entretanto não podemos esquecer que a CFS em si buscava atingir um fim. Assim, ela pode ser categorizada, de acordo com Hobsbawm $(1984 ; 1988)$ enquanto uma tradição inventada cujo propósito principal é a socialização, o inculcar de ideias, sistemas de valores e padrões de comportamento.

\section{Os CLUBES ESPORTIVOS E A CONSTRUÇÃO DE REPRESENTAÇÕES DA IDENTIDADE BRASILEIRA ATRAVÉS DA CORRIDA DO Fogo SiMBÓLICO}

Nesta seção procuramos abordar como os clubes esportivos, através da CFS, contribuíram para a construção da identidade nacional brasileira no imaginário dos porto-alegrenses. A invenção dessa tradição visava o processo de afirmação de normas e valores através da repetição durante o período de 1938 a 1947.

Cabe lembrar que o controle de qualquer publicação no período do Estado Novo (1937-1945) era feito por órgãos federais como, por exemplo, o Departamento de Imprensa e Propaganda (DIP). Grande parte das fontes impressas consultadas para este estudo possuía o carimbo do DIP e, provavelmente, possuíam o aval do Estado para serem publicadas. Sendo assim, as representações de construção da identidade nacional no imaginário porto-alegrense que dali são extraídas, podem trazer a concepção de quem às criou (CHARTIER, 1994).

Movimento, Porto Alegre, v. 15, n. 04, p. 11-33, outubro/dezembro de 2009. 


\section{Artigor Origimais Luis Henrique Rolim e Janice Z. Mazo}

A CFS estava inserida no processo de construção de uma identidade nacional brasileira (SMITH, 1997) proposta pelo Estado Novo. Essa tradição reforçava os laços de solidariedade entre os membros da sociedade partilhando mitos e memórias comuns. Neste sentido a CFS no período de 1938 a 1947 procurou construir uma representação de coesão ou unidade nacional no imaginário porto-alegrense. Essa representação se dava principalmente pelo formato de percorrer a nação - as cidades brasileiras - trazendo o Fogo da Pátria até a capital do Estado do Rio Grande do Sul - a cidade de Porto Alegre.

O quadro 1 demonstra o ano das edições, o significado atribuído a CFS e a relação dos quilômetros percorridos da nação até a cidade de Porto Alegre.

\begin{tabular}{|c|l|l|c|}
\hline Ano das edições & \multicolumn{1}{|c|}{ Local de saída da CFS } & \multicolumn{1}{|c|}{ Significado da CFS } & Km percorridos $^{7}$ \\
\hline 1938 & Viamão (RS- Brasil) & Alusiva a primeira capital do RS & 26 \\
\hline 1939 & Rio Pardo (RS - Brasil) & Alusiva a uma cidade cheia de tradições do RS & 411 \\
\hline 1940 & Florianópolis (SC - Brasil) & Alusiva a relação histórica existente nesta capital & 599 \\
\hline 1941 & São Paulo (SP - Brasil) & Alusiva ao local da Independência do Brasil & 2.123 \\
\hline 1942 & Tiradentes (MG - Brasil) & $\begin{array}{l}\text { Alusiva a Tiradentes, considerado o protomártir da } \\
\text { Independência brasileira }\end{array}$ & 3.974 \\
\hline 1943 & Salvador (BA - Brasil) & Alusiva a primeira capital do Brasil & 4.639 \\
\hline 1944 & Recife (PE - Brasil) & Alusiva aos heróis nacionais da Guerra dos Guararapes & 6.397 \\
\hline 1945 & Monte Castelo (Itália) & $\begin{array}{l}\text { Alusiva a participação brasileira na vitória dos aliados na } \\
\text { Segunda Guerra Mundial }\end{array}$ & 6.370 \\
\hline 1946 & $\begin{array}{l}\text { Washington } \\
\text { Estados Unidos da América) }\end{array}$ & Alusiva ao presidente norte-americano Franklin Roosevelt & 5.459 \\
\hline 1947 & Pistóia (Itália) & Alusiva aos soldados mortos na Segunda Guerra Mundial & 3.535 \\
\hline
\end{tabular}

Quadro 1. Edições da CFS

No quadro 1 podemos observar que o Fogo da Pátria se constituía em algo simbólico pelos valores agregados ao seu acendimento. ACFS apresentava deuses, como atletas e vultos históricos; sacerdotes, como autoridades e dirigentes esportivos; templos, como o Parque Farroupilha; imagens, como a Pira da Pátria; e ritos, como a CFS em si e o acendimento da Pira da Pátria. Dessa forma, a representação de unidade e coesão era reforçada pela construção de memórias comuns no imaginário dos porto-alegrenses.

\footnotetext{
${ }^{7}$ Existe uma discordância de quilometragem nas edições da CFS devido às diferentes fontes consultadas. Nesse resumo se adotou como primeira informação as provenientes da instituição que promovia a CFS a Liga de Defesa Nacional.
}

Movimento, Porto Alegre, v. 15, n. 04, p. 11-33, outubro/dezembro de 2009. 
Percebemos a construção da representação de unidade e coesão nacional, também através dos cartazes (SAFADY, 1960) que procuravam divulgar a CFS na cidade de Porto Alegre. Segundo Smith (1997, p. 58) a "[...] nação é uma comunidade de mitos e memórias comuns, tal como o é uma etnia". Assim a produção de cartazes pode ser pensada como uma estratégia para inculcar na população mitos e memórias comuns, reforçando a identidade nacional. Não bastava construir representações, era fundamental que fossem compartilhadas por todos.

A construção da representação da unidade nacional estava associada também a uma ideia de país vitorioso que contribuiu para a paz mundial sendo aliado dos Estados Unidos da América durante a II Guerra Mundial. Por outro lado, ao cruzar os diversos municípios do interior do Rio Grande do Sul que eram conhecidos pelas suas diferentes identidades étnicas reforçava-se a ideia de unidade em torno de uma única identidade: a nacional.

Lembramos que, no ano de 1939, a CFS passou por cidades como Santa Cruz, Venâncio Aires, Lajeado, Estrela, Taquari, Montenegro, São Sebastião do Caí, Novo Hamburgo e São Leopoldo (CORREIO DO POVO, 1939a). Essas cidades do interior do Rio Grande do Sul tinham uma expressiva população de imigrantes alemães e descendentes. Através de suas associações culturais e esportivas compartilhavam representações de identidades alemãs ou italianas.

Sendo assim, a CFS era uma prática cultural que contribuía para difundir os ideais nacionalistas e, consequentemente, a construção da unidade nacional, nos municípios do Rio Grande do Sul. Esse fato, de certa forma, poderia contribuir para a construção no imaginário porto-alegrense a ideia de que existia uma unidade nacional e que ela perpassava inclusive as cidades identificadas por outras identidades.

Nesse sentido Smith (1997) ressalta que para consolidar o seu domínio e homogeneizar a população numa nação compacta, a classe dirigente procura assimilar minorias étnicas através de um programa educacional de nacionalismo, apoiado por instituições influentes. Com este objetivo a CFS fomentava ideias de colonização e imagens oficiais da nação as quais toda a gente devia se ajustar. Assim impossibilitaria o aparecimento de quaisquer outras ideias, símbolos ou imagens mentais.

Movimento, Porto Alegre, v. 15, n. 04, p. 11-33, outubro/dezembro de 2009. 


\section{Artigos Orifinais Luis Henrique Rolim e Janice Z. Mazo}

De acordo com Oliven (1986, p. 72), o fenômeno da cultura no Brasil esteve centrado " [...] no processo de apropriação de manifestações culturais e sua subsequente transformação em símbolos de identidade nacional". Assim, os eventos cívicos, como a CFS, inscrevem-se entre aqueles que buscam inculcar na memória um acontecimento impondo crenças comuns à população ao traçar imagens fundadoras da nacionalidade. Neste sentido, esses eventos públicos são instrumentos eficazes para atingir o imaginário das pessoas e fomentar uma ideia de unidade nacional.

O êxito das cerimônias na construção da identidade nacional também está ligado às questões estéticas que ela promove, onde os sentimentos de beleza, de variedade, de dignidade e de ternura suscitados pela hábil disposição de formas, massas, sons e ritmos, podem evocar o espírito distinto da nação (SMITH, 1997). Além disso, essa construção de unidade nacional no imaginário porto-alegrense era reforçada pelos meios de comunicação da cidade de Porto Alegre. As rádios transmitiam boletins sobre a CFS (TORRES, 1997) e o jornal Correio do Povo (1939b, p. 3) exibia em sua seção de informes do interior as passagens da CFS pelas cidades:

Farroupilha (31/09 C.P.): "É esperada, hoje as vinte e uma hora, nesta cidade o 'fogo symbólico' que, vindo por Cahy, accenderá, a zero hora, a pyra do Altar da Pátria, levantado na cidade de Caxias"

Estrela (31/09 C.P.): "Chegou, hoje as quatro horas da madrugada, a tocha do fogo symbólico, que foi recebida na divisa do município de Lageado [...] Daqui a tocha seguiu as sete horas rumo a villa de Bom Retiro, onde chegou as oito horas"

Novo Hamburgo (31/09 por telefone): "Constitui um verdadeiro acontecimento a passagem por aqui do 'fogo symbólico' as 20,30 horas. O archote recebido na divisa deste município com o de São Leopoldo, no logar denominado de Boa Saúde"

Assim, a utilização de cerimônias como a CFS, faz parte de um reforço ao ideal a ser alcançado. Inclusive pode ser pensada como integrante de um programa educacional de nacionalismo e de seus

Movimento, Porto Alegre, v. 15, n. 04, p. 11-33, outubro/dezembro de 2009. 
valores agregados. O seu caráter repetitivo serve para recordar os seus cidadãos dos seus laços culturais e seu parentesco político, reafirmando a identidade e a unidade (SMITH, 1997).

Não devemos esquecer que assim como no interior do Rio Grande do Sul o associativismo esportivo em Porto Alegre desde meados do século XIX até o final da década de 1930 era fortemente marcado pelas diferentes etnias que fundaram os primeiros clubes na cidade. Ao longo desse período, os clubes se constituíram em espaços de construção de representações de identidade culturais, principalmente dos imigrantes alemães e italianos e seus descendentes (MAZO, 2003).

O panorama esportivo porto-alegrense era composto por clubes, associações, sociedades, ligas, comitês e federações que buscavam exaltar, além das práticas esportivas, diferentes representações da sua matriz cultural. Com o advento do Estado Novo e, principalmente pela atuação do núcleo regional da LDN, os clubes esportivos de Porto Alegre tiveram que se 'moldar' às exigências das ações nacionalizadoras que entraram em vigor no país. Já não eram mais permitidas manifestações culturais identificadas com a pátria de origem dos imigrantes e descendentes. Diante desse contexto podemos inferir que se desencadeou uma luta de representações de identidades culturais na cidade, entre os clubes considerados estrangeiros, pois seus pioneiros eram imigrantes alemães ou italianos, com os vistos de nacionais.

Assim, os clubes esportivos deveriam demonstrar seu sentimento patriótico se engajando nas comemorações da Semana da Pátria, dentre elas a CFS. O patriotismo dos clubes esportivos era atestado pela LDN, que conferia um diploma de participação para as associações que desfilavam na Semana da Pátria (MAZO; ROLIM, 2007). Entretanto, a 'rede de contatos' que deveria existir entre Túlio De Rose, José Carlos Daudt, Ernesto Cappeli e Darci Vignoli, alguns dos dirigentes de clubes esportivos da cidade de Porto Alegre, pode ter facilitado a participação dos clubes na CFS.

José Carlos Daudt participava da Turnerbund e era representante da Liga Atlética Rio Grandense, instituição que havia destacado alguns atletas para participar da $1^{\mathrm{a}}$ edição da CFS (CORREIO DO POVO, 1938b). Túlio De Rose e Ernesto Cappeli participavam do Club

Movimento, Porto Alegre, v. 15, n. 04, p. 11-33, outubro/dezembro de 2009. 


\section{Artigos Orifinais Luis Henrique Rolim e Janice Z. Mazo}

Italiano Canottieri Duca degli Abruzzi, entretanto Túlio De Rose "[...] conseguia dispensa de três meses do jornal Correio do Povo para organizar a CFS" (entrevistado MT). Ernesto Cappeli não obtinha das mesmas vantagens em suas atividades, fato esse que o afastou da organização da CFS. Túlio De Rose tinha como amigo próximo Darci Vignoli. Darci Vignoli participava da Turnershafe da Liga Náutica, sendo ainda posteriormente membro do núcleo regional da Liga de Defesa Nacional, presidindo o núcleo regional que tinha grande apoio do governo devido "[...] aos laços de amizade dele com Getúlio Vargas" (Entrevistado HL).

Nesse sentido os dirigentes ao se associarem a CFS “[...] buscavam defender os interesses dos seus clubes, pensando no desenvolvimento do esporte da cidade de Porto Alegre" (entrevistado HL). As medidas de retaliação que muitos clubes sofriam devido às matrizes culturais que possuíam podem ter servido de alerta para que os dirigentes esportivos aderissem aos projetos nacionalistas.

Assim ao 'ceder seus atletas ao Brasil', os dirigentes estariam colaborando com a construção da identidade nacional através da CFS $\mathrm{e}$, consequentemente, poderiam pensar que estavam aliviando seus clubes das medidas retaliativas impostas pela nacionalização. O qua-

\begin{tabular}{|c|c|c|c|}
\hline Ano da CFS & Nome do Atleta & Clube esportivo & Trecho percorrido \\
\hline \multirow{4}{*}{1938} & Mário Rosa & Não identificado & Passo do Sabão \\
\hline & Casemiro Marinho & Grêmio Foot Ball Porto Alegrense & Bairro Parthenon \\
\hline & Carlos Alencastro & Não identificado & Avenida João Pessoa \\
\hline & Otto Ritter & Turnerbund & Acendeu o Fogo na Pira da Pátria \\
\hline 1939 & Lauro Kliemann & Turnerbund & Acendeu o Fogo na Pira da Pátria \\
\hline 1940 & Antônio Pereira Lira & Não identificado & Acendeu o Fogo na Pira da Pátria \\
\hline 1941 & Arno Franzen & Clube de Regatas Almirante Barroso & $\begin{array}{l}\text { Conduziu a tocha da Igreja do Rosário até } \\
\text { o acendimento da Pira }\end{array}$ \\
\hline \multirow{4}{*}{1942} & Oscar Barbosa dos Santos & Não identificado & Acendeu o Fogo na Pira da Pátria \\
\hline & Antonio Rosa & Não identificado & Escoltou o Fogo até a Pira \\
\hline & Eugênio Carlos Pinto & Não identificado & Escoltou o Fogo até a Pira \\
\hline & Otto Ritter & Turnerbund & $\begin{array}{l}\text { Conduziu até a Igreja Nossa Senhora das } \\
\text { Dores }\end{array}$ \\
\hline \multirow{2}{*}{1943} & Carlos Eugênio Pinto & Não identificado & Acendeu o Fogo na Pira da Pátria \\
\hline & Mario Nascimento Medeiros & Não identificado & Escoltou o Fogo até a Pira \\
\hline 1944 & Darci Jardim & Grêmio Esportivo Renner & Acendeu a Pira em Porto Alegre \\
\hline 1945 & Érika Renner & Turnerbund & Conduziu o Fogo até a Pira \\
\hline 1946 & Carlos Montagna & Não identificado & Acendeu a Pira em Porto Alegre \\
\hline 1947 & Túlio De Rose & Cannotieri Duca degli Abruzzi & Carregou a tocha desde Pistóia, Itália \\
\hline
\end{tabular}

Quadro 2. Atletas que carregaram a o Fogo Simbólico

Movimento, Porto Alegre, v. 15, n. 04, p. 11-33, outubro/dezembro de 2009. 
dro 2 apresenta a participação de atletas de clubes esportivos portoalegrenses na CFS no trecho da cidade de Porto Alegre.

O quadro 2 sugere que os clubes esportivos porto-alegrenses na figura dos seus atletas e dirigentes que se associavam a CFS, buscavam construir a representação de integração do esporte porto-alegrense, antes marcado pelas diferentes etnias, no projeto de construção da identidade nacional brasileira.

Entretanto, é interessante pensar que a construção da representação de integração do esporte porto-alegrense sofria resistências. Havia uma luta de representações que se constituiu também através dos atletas envolvidos na CFS. A dinâmica de 'luta de representações' pode ser evidenciada nos uniformes dos clubes esportivos de origem que os atletas utilizavam ao percorrer as ruas de Porto Alegre. Além disso, a forma como as publicações tratavam alguns atletas poder-se-ia evidenciar essa luta de representações.

Nesse sentido, o jornal Correio do Povo descreve que a honra de acender a Pira da Pátria foi de "Lauro Kliemann da Turner-Bund, campeão sul americano de fundo" (CORREIO DO POVO, 1939a). Já na publicação da LDN o atleta é "João Lauro Kliemann - campeão brasileiro de 800 metros" (SAFADY, 1960, p. 66). Dessa forma podemos pensar que, ao mesmo tempo em que eram heróis da nação e colaboravam com a construção da identidade nacional, eles representavam uma preservação da identidade com seus clubes de origem.

Cabe lembrar que os atletas - veteranos, universitários, militares, escolares - que carregaram o Fogo Simbólico da Pátria entre os anos de 1938 e 1947 eram provenientes dos mais diversos clubes esportivos da cidade de Porto Alegre. Contudo, a honra do acendimento da Pira da Pátria, ou seja, o último portador do Fogo Simbólico da Pátria no revezamento era de um atleta de destaque nos clubes esportivos que representava, nessa luta de representações, um destaque nacional.

Conforme Smith (1997) são as ideias e as doutrinas específicas, entrelaçadas em tradições ressaltadas como antigas, que fornecem o simbolismo e o cerimonial que despertam as mais profundas emoções e aspirações populares. Nesse sentido a instalação da doutrina específica na CFS se dá através das instituições e pessoas ligadas a ela.

Movimento, Porto Alegre, v. 15, n. 04, p. 11-33, outubro/dezembro de 2009. 


\section{Antigos Originais Luis Henrique Rolim e Janice Z. Mazo}

A Liga de Defesa Nacional, enquanto instituição oficial e, os dirigentes esportivos porto-alegrenses, enquanto colaboradores desse processo faziam parte da instalação da identidade nacional no contexto porto-alegrense. Entretanto, entendemos que a instituição social feita pelos clubes foi determinante para CFS passar a ser reconhecida pelos porto-alegrenses e compartilhada pela coletividade. Assim a cada ano, no mês de setembro, essa coletividade renovava seus sentimentos de pertencimento à nação brasileira.

\section{Considerações finaIS}

Buscou-se compreender como ocorreu a participação dos clubes esportivos na invenção da Corrida de Revezamento do Fogo Simbólico da Pátria (CFS) em Porto Alegre no período de 1938 a 1947. Entretanto, para além dos clubes esportivos porto-alegrenses, o estudo sobre a CFS pode ajudar a compreender também a importância dada às práticas esportivas no período do Estado Novo no Brasil. Neste sentido, evidenciou-se que ao se engajarem no processo de invenção e fixação da CFS, os clubes esportivos construíram representações de uma identidade nacional brasileira no imaginário porto-alegrense. Podemos entender a CFS no período estudado como uma tradição historicamente original e livremente inventada e podemos considerar uma cerimônia que procurava forjar nos porto-alegrenses a consciência da sua cidadania.

Os mecanismos governamentais criados para a construção de uma identidade nacional brasileira no Estado do Rio Grande do Sul e principalmente em Porto Alegre, foram reforçados pela invenção da CFS, fato esse justificado no seu aparecimento e fixação ao longo do período estudado. Além disso, a instituição social feita pelos clubes, principalmente pelos dirigentes esportivos porto-alegrenses que estiveram presentes na Cerimônia de Abertura dos Jogos de Berlim, fez com que a CFS, pudesse atingir o imaginário dos porto-alegrenses com representações de unidade e coesão nacional.

No momento político em que se buscava afirmar uma identidade nacional brasileira, a CFS pode ser vista como uma das ações nacionalizadoras do país produzidas no campo cultural-esportivo. A relevância

Movimento, Porto Alegre, v. 15, n. 04, p. 11-33, outubro/dezembro de 2009. 
dada a CFS no período estudado permite afirmar que sua ação nacionalizadora era de certa forma eficiente. Ao extrapolar as fronteiras do país, foi considerada a maior corrida de revezamento em nível simbólico do mundo, pois a Corrida de Revezamento da Chama Olímpica somente retornou a cena mundial no ano de 1948.

Esse destaque atribuído a CFS parece ultrapassar os limites da sua ação nacionalizadora para se configurar uma tentativa de colocar o Brasil em evidência no cenário mundial. Ao realizar a CFS o país estava mostrando suas virtudes políticas de organização e administração do país através da realização de uma prática cultural com características olímpicas. Dessa forma, o apoio do governo a CFS pode ser entendido enquanto uma das formas para buscar o alinhamento do país às grandes potências mundiais, que também se revelavam como tal, através dos eventos olímpicos.

Essa alusão reforça a ideia de que o estudo histórico sobre esporte e suas práticas associadas merecem uma atenção diferenciada, para que possamos ter um entendimento das relações políticas e sociais que permeiam o campo esportivo. Considera-se que a busca por fontes impressas em localidades fora do país, principalmente nas cidades por onde a CFS perpassou, poderá contribuir com outras interpretações sobre a CFS. Além disso, a ampliação, tanto das fontes impressas, quanto orais, possibilitariam diferentes olhares para o estudo da CFS, visto que as fontes consultadas nesse estudo estavam limitadas pelos mecanismos de controle criados pelo governo brasileiro no período do Estado Novo.

Movimento, Porto Alegre, v. 15, n. 04, p. 11-33, outubro/dezembro de 2009. 


\section{Artifos Orifinais Luis Henrique Rolim e Janice Z. Mazo}

The National Torch Relay in Porto Alegre city (1938-
1947): study on the sports clubs participation
Abstract: This study aims to understand the porto-
alegrenses sports clubs participation in the invention
of the National Torch Relay (NTR) in Porto Alegre city
(RS - Brazil) in the period from 1938 to 1947. Printed and
oral sources were used in it. Porto-alegrenses sports
clubs, in the figure of their athletes and sports leaders,
helped to invent and set the NTR in Porto Alegre city.
Moreover, the sports clubs constructed representations
of the Brazilian national identity through the NTR.
Key words: Sports Clubs. Running. History

Carrera de Relevo del Fuego Simbólico de La Nación en Porto Alegre (1938-1947): estudio sobre la participación de los clubes deportivos Resumen: Este estudio tiene como objetivo entender la participación de los clubes deportivos portoalegrenses en la invención de la "Carrera de relevo del Fuego Simbólico de la Nación» (CFS) en la ciudad de Porto Alegre (RS - Brasil) en el período comprendido entre 1938 a 1947. Fuentes impresas y fuentes orales fueron utilizadas en ese estudio. Los clubes deportivos porto-alegrenses, en la figura de sus atletas y dirigentes, han ayudado a inventar y establecer la CFS en Porto Alegre. Por otra parte, los clubes esportivos construiran representaciones de la identidad nacional brasileña a través de la CFS.

Palabras clave: Clubes Deportivos. Carrera. Historia.

\section{REFERÊNCIAS}

AMARO JÚNIOR, J. As aventuras do Fogo Simbólico, e de seu idealizador entre nós, o jornalista Túlio de Rose. Revista do Globo, Porto Alegre, n. 369, p.40-41, 19 ago., 1944.

Almanaque Esportivo do Rio Grande do Sul. Porto Alegre: Tipografia Esperança, 1947. v. 6.

BARDIN, L. Análise de Conteúdo. Lisboa: Edições 70, 2000.

BILHAR, F. C.; OLIVEN, R. G. A centelha da chama crioula e o reascender da identidade gaúcha. In: SALÃO DE INICIAÇÃO CIENTÍFICA, UFRGS $(23,2006)$. Livro de Resumos. Porto Alegre: UFRGS, 2006. p.797.

BORGERS, W. Olympic torch relays: 1936-1994. Cologne: International Olympic Committee; Olympic Research Institute of the German Sport University, 1996.

Movimento, Porto Alegre, v. 15, n. 04, p. 11-33, outubro/dezembro de 2009. 
BURKE, P. O que é história cultural? Rio de Janeiro: Jorge Zahar, 2005.

CASTRO, C. In corpore sano - os militares e a introdução da educação física no Brasil. Antropolítica, Niterói, RJ, n. 2, p.61-78, 1 semestre de 1997.

CHARTIER, R. A História Hoje: dúvidas, desafios, propostas. Estudos Históricos, Rio de Janeiro, v. 7, n. 13, p.97-113, 1994.

A história cultural: entre práticas e representações. Lisboa: DIFEL, 2000.

CORREIO DO POVO. Correio do Povo, Porto Alegre, 1 set. 1938a.

Correio do Povo, Porto Alegre, 1 set. 1938b.

A CORRIDA do Fogo Symbolico. Correio do Povo, Porto Alegre, p.11, 1 set. 1938a. Noticiário.

DALMÁZ, M. A imagem do Terceiro Reich na Revista do Globo (1933-1945). Porto Alegre: EDIPUCRS, 2002.

DAUDT, J. C. Brasileiros de cabelos loiros e olhos azuis. Porto Alegre: Catos, 1952.

O FOGO da Pátria. Correio do Povo, Porto Alegre, p.5, 7 set. 1938a. Editoreaes (João Henrique), parte I.

parte II.

Correio do Povo, Porto Alegre, p.5, 9 set. 1938b. Editoreaes (João Henrique), parte III.

Correio do Povo, Porto Alegre, p.5, 11 set. 1938c. Editoreaes (João Henrique),

FONSECA, N. A maior corrida do Brasil. Revista do Globo, Porto Alegre, n. 803, p.6673, 1961.

HOBSBAWM, E.; RANGER, T. (Org.) A invenção das tradições. 2. ed. Rio de Janeiro: Paz e Terra, 1984.

HOBSBAWM, E. Tradições inventadas. Lisboa: Ministério da Educação. Direç̧ãoGeral dos Desportos, 1988.

INICIADA a Semana da Pátria. Correio do Povo, Porto Alegre, p.10, 1 set. 1944. Noticiário.

INICIARAM-SE os festejos da Semana da Pátria. Correio do Povo, Porto Alegre, p.03, 1 set. 1939b. Noticiário.

INTERNATIONAL OLYMPIC COMMITTEE. The Olympic symbols. Lausanne: Olympic Museum and Studies Centre, 2002.

LIGA DA DEFESA NACIONAL. Diretoria Estadual do Rio Grande do Sul. Boletim Informativo das Atividades Cívicas. Porto Alegre, 1983.

Movimento, Porto Alegre, v. 15, n. 04, p. 11-33, outubro/dezembro de 2009. 


\section{Artigos Orifinais Luis Henrique Rolim e Janice Z. Mazo}

Corridas do Fogo Simbólico. Porto Alegre, 2006. Disponível em: <http:/ /www.ligadadefesanacional.org.br/index.htm>. Acesso em: 25 set. 2006.

MAZO, J. Z. A emergência e a Expansão do Associativismo Desportivo em Porto Alegre (1867-1945): espaço de representação da identidade cultural brasileira. Tese (Doutorado em Educação Física) - Universidade do Porto (UP). Porto, Portugal, 2003.

MAZO, J. Z.; ROLIM, L. H. Memórias da participação dos clubes esportivos nas comemorações da Semana da Pátria em Porto Alegre (décadas de 1930 e 1940). In: GOELLNER, S. V.; JAEGER, A. A. Garimpando memórias: esporte, educação física, lazer e dança. Porto Alegre: Editora da UFRGS, 2007.

MAZZONI, T. Almanaque Esportivo: Olympicus. São Paulo: Publicidade Sem Rival, $1943 / 1944$

MONTEIRO, C. A inscrição da modernidade no espaço urbano de Porto Alegre (1924-1928). Dissertação (Mestrado em História do Brasil) - Programa de Pós-Graduação em História, Universidade Federal do Rio Grande do Sul, Porto Alegre, 1992.

MORAES, R. Análise de Conteúdo. Revista Educação da PUCRS, Porto Alegre, n. 37, p.7-32, março de 1999.

OLIVEN, R. Violência e cultura no Brasil. 3. ed. Petrópolis: Vozes, 1986.

PAIXÃO CORTES, J. C. Origem da Semana Farroupilha e Primórdios do Movimento Tradicionalista. Porto Alegre: EVANGRAF, 1994.

PIMENTEL, F. Aspectos Gerais de Pôrto Alegre. Porto Alegre: Oficinas Gráficas da Imprensa Oficial, 1945. v. 1.

PESAVENTO, S. J. História \& história cultural. Belo Horizonte: Autêntica, 2004.

De como os alemães se tornaram gaúchos pelo caminho da modernização. In: MAUCH, C.; VASCONCELLOS, N. (Org.). Os alemães no sul do Brasil. Canoas: Editora da ULBRA, 1994. p.199-220.

ROLIM, L. H. A chama que arde em nossos clubes!: a corrida de revezamento do fogo simbólico de pátria em Porto Alegre (1938-1947). Dissertação (Mestrado) Escola de Educação Física, Universidade Federal do Rio Grande do Sul, Porto Alegre, 2008.

SAFADY, J. S. Liga de Defesa Nacional: fogo simbólico da pátria (sinopse). São Paulo: Safady , 1960

Liga de Defesa Nacional: fogo simbólico da pátria (terceira sinopse segunda edição). São Paulo: Safady, 1971.

SMITH, A. A identidade nacional. Lisboa: Gradiva, 1997.

Movimento, Porto Alegre, v. 15, n. 04, p. 11-33, outubro/dezembro de 2009. 
TORRES, A. S. A campanha nacionalizadora cívico-educativa e a Semana da Pátria na Imprensa de Porto Alegre (1937-1945). Dissertação (Mestrado em História) - Programa de Pós-Graduação em História, Pontifícia Universidade Católica do Rio Grande do Sul, Porto Alegre, 1997.

TRIVIÑOS, A. Introdução à pesquisa em ciências sociais: a pesquisa qualitativa em educação. São Paulo: Atlas, 1987.

Recebido em: 01.09.2008

Aprovado em: 04.08.2009

Movimento, Porto Alegre, v. 15, n. 04, p. 11-33, outubro/dezembro de 2009. 